\title{
Políticas Públicas e Targeting Setorial — Efeitos da Nova Política Industrial sobre o Setor Automobilístico Brasileiro
}

\author{
Public policies and sectorial targets \\ The effects of the new industrial policy on the \\ Brazilian automobile sector
}

EDUARDO MEIRA ZAULI*

RESUMO: Este artigo analisa as novas condições criadas pelo Regime Automotivo Brasileiro desde o segundo semestre de 1995. Primeiro, discute as principais controvérsias em torno da implementação de uma nova modalidade de política industrial por parte do governo federal e os incentivos concedidos pelo Estado governos às empresas do setor automobilístico no Brasil. Segundo, o artigo esboça uma imagem da situação desse setor industrial, com ênfase nas mudanças que estão acontecendo nas relações entre a indústria de montagem e a indústria de autopeças. No contexto do novo clima de competição criado pelas tendências à globalização dos mercados e pelas novas diretrizes da política industrial em vigor, este artigo mostra que novos modos de governança nas relações entre as montadoras locais e seus fornecedores são importantes. substituindo as antigas estratégias competitivas.

PALAVRAS-CHAVE: Política industrial; regime automotivo brasileiro; setor automotivo.

ABSTRACT: This article examines the new conditions created by the Brazilian Automotive Regime since the second semester of 1995. First, it discusses the main controversies surrounding the implementation of a new modality of industrial policy on the part of the federal government and the incentives granted by the state governments to the companies of the automobile sector in Brazil. Second, this article sketches a picture of the situation of this industrial sector, with emphasis on the changes that are happening in the relationships between assembling industry and auto parts industry. In the context of the new climate of competition created by the tendencies towards globalization of markets and by the new guidelines of the industrial politics in place, this article shows that new modes of governance in the relations between the local "montadoras" and their providers are replacing the old competitive strategies.

KEYWORDS: Industrial policy; Brazilian automotive regime; automotive sector.

JEL Classification: L62; L52.

\footnotetext{
* Professor do Departamento de Ciência Política da Universidade Federal de Minas Gerais - UFMG, Belo Horizonte/MG, Brasil. E-mail: zauli@fafich.ufmg.br..
} 


\section{INTRODUÇÃO}

A indústria automobilística mundial vem passando por um processo de reestruturação de larga escala que tem impactado diretamente as condições da concorrência neste setor da economia. Em termos globais, este setor da indústria opera hoje com uma capacidade ociosa da ordem de $30 \%$ em um contexto caracterizado pelo lento crescimento da demanda por seus produtos nos EUA, Europa e Japão, e pelo aumento da capacidade de produção global derivado de novos investimentos. Mais do que um fenômeno de natureza cíclica, a estagnação da demanda por produtos da indústria automobilística é reflexo da saturação da demanda em mercados maduros nos principais centros produtores dos países centrais. ${ }^{1}$

Diante da progressiva abertura de mercados nacionais até então relativamente protegidos e do crescimento da concorrência de novos produtores, a atenção das grandes corporações do setor volta-se para os mercados emergentes que adquirem importância crescente em suas estratégias de market share (Freyssenet \& Lung, 1996). Nestas circunstâncias, ao lado da Ásia, agora imersa em uma crise cujas proporções ainda são desconhecidas, a América Latina tem concentrado boa parte das atenções e dos novos investimentos no setor automobilístico, anunciados nos últimos anos por parte de um grande número de montadoras e fornecedores, na expectativa de poderem se beneficiar da expansão dos mercados dos países da região.

No contexto latino-americano, a economia brasileira tem-se destacado enquanto pólo de atração e localização de novos investimentos na cadeia produtiva do setor em decorrência de avaliações favoráveis por parte dos investidores a respeito da expansão de seu mercado interno, em decorrência de sua inserção no âmbito do Mercosul e de seu potencial enquanto plataforma exportadora de produtos destinados ao mercado internacional (AMCHAM Brasil, 1997; Santos, 1997).

Não obstante a pequena participação da produção dos países membros do Mercosul no total da produção da indústria automobilística mundial, os progressos na direção de uma maior integração e as perspectivas de crescimento da produção intrazona têm estimulado diversas empresas a realizarem novos investimentos e a constituírem novas unidades de negócios de âmbito regional em um contexto marcado pela busca de maiores níveis de complementaridade entre plantas industriais localizadas em diferentes países (BNDES, 19956).

A partir de um diagnóstico relativo às perspectivas de internalização de novos segmentos do setor automobilístico mundial e de ampliação da capacidade produtiva e exportadora dos produtores aqui localizados, e em meio às vicissitudes conjunturais da economia brasileira, a partir do $2^{\circ}$ semestre de 1995 o governo federal passa a adotar, como se verá a seguir, um conjunto de medidas consubstanciadas em um Regime Automotivo, destinadas a atrair novos investimentos. Conformando as condições a partir das quais vai ocorrer uma segunda onda de grandes investimentos em diferentes pontos da cadeia produtiva do setor automobilístico no

1 “Uma indústria congestionada”. In: Gazeta Mercantil, 16, 17, 18/05/97 
Brasil, em resposta às iniciativas governamentais vultosos investimentos têm sido anunciados por diferentes empresas produtoras já instaladas em nosso mercado e por newcomers, alguns dos quais até então haviam se limitado a comercializar seus produtos no país através de exportações de unidades localizadas fora do Brasil. ${ }^{2}$

Este artigo estrutura-se em torno da hipótese de que, no contexto de transformações em escala internacional na configuração da indústria automobilística, e a partir do processo de abertura comercial no Brasil e implementação de novos padrões de política industrial por parte do governo federal, observa-se a ocorrência de mudanças estruturais na articulação entre empresas montadoras e fornecedoras de autopeças.

\section{OS REGIMES AUTOMOTIVOS NACIONAL E ESPECIAL}

No âmbito das negociações relativas à constituição do Mercosul, Brasil, Argentina, Uruguai e Paraguai assumiram o compromisso, em dezembro de 1994 (Encontro de Ouro Preto), de estabelecer um regime automotivo comum até 31 de dezembro de 1997, a ser adotado a partir de $1^{\circ}$ de janeiro de 2000 . As diretrizes básicas a serem perseguidas envolviam: a liberalização total do comércio intrazona, o estabelecimento de uma tarifa externa comum e a ausência de incentivos nacionais especiais.

De parte da Argentina, reconheciam-se como nacionais as autopeças brasileiras dentro do cômputo do índice de conteúdo nacional do programa setorial argentino, tendo como contrapartida o requisito de compensação com exportações a qualquer destino, sendo que as exportações argentinas de autopeças dirigidas ao Brasil eram multiplicadas por 1,2 para a compensação das autopeças importadas desse país. Do lado do Brasil, consideravam-se como nacionais as autopeças argentinas para cumprir com o requisito de conteúdo nacional previsto no programa do "carro popular", bem como os veículos argentinos que cumprissem com as exigências deste programa. Estabeleceu-se ainda o livre comércio de autoveículos sem qualquer barreira tarifária ou sistema de cotas. Foi acertado ainda o estabelecimento de duas cotas de exportação sem compensação: uma para as montadoras instaladas em apenas um dos países; e a outra em benefício da Argentina, em função do déficit comercial bilateral acumulado frente ao Brasil entre 1991 e 1994.

A despeito dos acordos anteriores, tendo em vista a deterioração de nossas contas externas, as intervenções do Estado na área da políticas públicas voltadas para o setor automobilístico a partir do $2^{\circ}$ semestre de 1995 passam a ser condicionadas pela avaliação de que o desempenho de alguns dos indicadores da performance da economia nacional eram insustentáveis no médio prazo.

\footnotetext{
${ }^{2}$ A propósito dos preparativos para enfrentar os desafios estratégicos com que se deparam Volkswagen e General Motors, as duas maiores montadoras localizadas no Brasil, vejam-se "Doktor Demel chegou", in: Exame, 16/07/97, e "O homem que tem gasolina nas veias", in: Exame, 10/09/97.
} 
As medidas de liberalização comercial e o recurso à uma âncora cambial visando a estabilidade de preços elevaram substancialmente o nível das importações na economia brasileira e, particularmente, das importações de autoveículos, com efeitos consideráveis sobre a balança comercial. Graças às medidas liberalizantes do comércio exterior e à valorização do Real, 177.738.000 autoveículos importados ingressaram no mercado brasileiro no ano de $1994 \mathrm{e}$, mantidas as condições que propiciaram tamanha elevação do volume de importações, cerca de $600 \mathrm{mil}$ novos autoveículos seriam importados ao longo de 1995. De fato, ao longo de 1995, 409.933.000 autoveículos foram importados pelo Brasil, o que implicou em gastos da ordem de US\$ 4.795.300.000,00. ${ }^{3}$

Precedidas de consultas junto a diversos atores participantes dos interesses organizados no âmbito do complexo automotivo, as diversas medidas provisórias destinadas, primeiro à criação, depois à manutenção provisória dos incentivos ao setor automobilístico, bem como o Decreto ${ }^{\circ} 1.761$ (26/12/95) se constituem em uma resposta do governo brasileiro ao crescimento das importações do setor automobilístico e à necessidade de adequação das políticas para o setor ao regime automotivo argentino.

Criado em dezembro de 1991, e com prazo de validade até dezembro de 1999, o regime automotivo argentino buscava assegurar uma série de estímulos à produção interna de autoveículos (Roldán, 1996). Adotado em um momento em que no Brasil se procedia a uma relativa liberalização das importações, o regime automotivo argentino acabou por produzir um forte viés a favor de nosso principal parceiro comercial no Mercosul na atração de novos investimentos para o setor.

Em resposta a essa situação, através do decreto n. ${ }^{\circ} 1.761$, o governo federal estabeleceu, entre outras medidas, a adoção de:

1. um índice médio de nacionalização de $60 \%$ aplicável aos newcomers depois de um período de carência de três anos;

2. definição de cotas de importação com imposto reduzido correspondentes às exportações adicionais correspondentes a $20 \%$ sobre o valor FOB das exportações de produtos de fabricação própria; 100\% (1996/1997), 95\% (1988) e 70\% (1999) do valor FOB das importações de equipamentos incorporados ao ativo permanente das empresas; $140 \%$ (1996), 120\% (1997), 95\% (1998) e 70\% (1999) das aquisições de bens de capital fabricados no país;

3. redução do Imposto de Importação, até 31/12/99, correspondente a $90 \%$ para bens de capital; 85\% (1996), 70\% (1997), 55\% (1998), 40\% (1999) para insumos; e redução de 50\%, até 1999, do Imposto de Importação de veículos de transporte pelas montadoras locais.

Instituído inicialmente por medida provisória em julho de 1995 (medida pro-

\footnotetext{
${ }^{3}$ Banco Central do Brasil.
} 
visória $\mathrm{n}^{\circ}$ 1.024), e aprovado como projeto de lei em 13 de março de 1997 (medida provisória $\mathrm{n}^{\circ} 1536$ ), o regime automotivo brasileiro consiste basicamente em um conjunto de medidas de estímulo aos investimentos e às exportações do setor. Mediante a assinatura de um termo de adesão à política de incentivos em questão, as indústrias se habilitam a usufruir de um regime especial de tarifas preferenciais para suas importações de matérias-primas, insumos, partes, peças e bens de capital, sujeitas a requisitos de desempenho (mecanismo de intercâmbio compensado), gozando ainda as montadoras locais do direito de importar veículos com uma preferência tarifária de $50 \%$.

Em meio às negociações relativas à aprovação da medida provisória do Regime Automotivo, e diante da perspectiva de votação de um projeto de conversão que diminuía os incentivos para as indústrias do setor automotivo instaladas nas regiões Sul e Sudeste, transferindo-os para outras regiões, as bancadas parlamentares dos estados das regiões Norte, Nordeste e Centro-Oeste lograram a aceitação por parte do Executivo federal em estabelecer um regime automotivo especial para as indústrias localizadas nos estados daquelas três regiões (medida provisória $\mathrm{n}^{\circ}$ $1532-13$ /03/97).

Embora coerente com a proposta original que informou a constituição do Regime Automotivo em junho de 1995, a política então adotada em relação às regiões Norte, Nordeste e Centro-Oeste se constituía em um conjunto de incentivos ainda maiores em relação àqueles concedidos às indústrias das demais regiões. ${ }^{4}$

A princípio, o prazo de adesão ao regime especial deveria encerrar-se em 31 de março de 1997. Entretanto, como até meados deste mês apenas a empresa coreana Asia Motors havia anunciado sua decisão de investir na construção de uma fábrica na Bahia, o prazo de adesão ao regime especial terminou sendo fixado pelo Congresso Nacional em 31 de maio de 1997 para as empresas montadoras e em 31 de março de 1998 para as empresas de autopeças. A expectativa era de que, com esse novo prazo de adesão, outros estados em processo de negociação com investidores potenciais, particularmente Pernambuco, estado do vice-presidente da República Marco Maciel, tivessem mais tempo para atrair outros investimentos.

Com prazo de vigência até o ano de 2010, este regime especial tem como características mais importantes na área fiscal:

1) redução de $100 \%$ do Imposto de Importação sobre bens de capital;

2) redução de $90 \%$ do Imposto de Importação sobre insumos;

3) redução de até 50 \% do Imposto de Importação sobre veículos;

4) isenção de IPI incidente na aquisição de bens de capital;

5) redução de $45 \%$ do IPI na aquisição de insumos;

6) isenção do Adicional ao Frete para Renovação da Marinha Mercante;

\footnotetext{
${ }^{4}$ Note-se que nem todos os novos investimentos nas regiões Norte, Nordeste e Centro-Oeste têm sido feitos no âmbito do regime automotivo especial. Este é o caso, por exemplo, da nova fábrica de caminhonetes Mitsubishi, um empreendimento conjunto com a MMC Automóveis (importador oficial da marca no Brasil) em Goiás.
} 
7) isenção do IOF nas operações de câmbio para pagamento de bens importados;

8) isenção do Imposto de Renda sobre o lucro do empreendimento;

9) crédito presumido de IPI, com ressarcimento em dobro de contribuições, como o PIS e a COFINS.

Quanto às exigências relativas aos índices de nacionalização:

1) para fabricantes de veículos com mais de três rodas: no mínimo, $50 \%$; sobe para $60 \%$ em 2002 ;

2) para fabricantes de veículos de duas rodas: no mínimo, $60 \%$ até 2001 ; de pois, $70 \%$.

Consta ainda da medida provisória:

1) limite de importação de $30 \%$ dos investimentos efetivados pela empresa periodicamente;

2) importação de bens de capital com benefícios: será limitada ao valor das compras internas desses produtos (proporção de 1 para 1 ) até 31/12/97. Depois, passa a 1 para 1,5 ;

3) importação de matéria-prima com benefícios: será limitada à proporção de 1 para 1 ;

4) importações de insumos não poderão exceder a dois terços das exportações líquidas da empresa (inclui $40 \%$ das vendas externas, 100\% dos gastos com treinamento de mão-de-obra, $200 \%$ dos gastos com bens de capital de origem nacional, $150 \%$ do valor de importações de ferramentas e $100 \%$ dos gastos com construção civil);

5) bônus de importação: $200 \%$ sobre o valor das compras de equipamentos nacionais, e $150 \%$ para equipamentos importados.

Como contrapartida às medidas adotadas no âmbito do regime automotivo nacional, o governo brasileiro passou a adotar a partir de julho de 1996 cotas de exportação com base em critérios de desempenho de exportações para empresas não instaladas no país, respeitado o limite máximo geral de 50 mil veículos/ano, com prazo de vigência até 1999 . Diante de uma tarifa normal de importação de $63 \%$, os veículos da cota de cada exportador poderiam ser importados com uma alíquota reduzida de $35 \%$.

Desde os acordos da câmara setorial da indústria automotiva em 1992/93, observa-se uma significativa retomada dos investimentos na cadeia produtiva do setor automobilístico no Brasil. Superado o quadro de crise que marcou o setor no final dos anos 80 e início dos anos 90, é no mercado brasileiro que estão programados os maiores investimentos da indústria automobilística mundial.

Os investimentos já realizados e aqueles que têm sido anunciados destinam-se à instalação de novas plantas e à ampliação e diversificação de plantas já existentes de indústrias montadoras e de fornecedores de componentes. Só no âmbito do regime automotivo especial, foram anunciados investimentos da ordem de US\$ 3,51 bilhões em diferentes estados das regiões Norte, Centro-Oeste e Nordeste. As pers- 
pectivas são de que as novas inversões no setor coloque o Brasil na condição de sexto produtor no ranking mundial.

Embora a viabilidade dos novos investimentos no setor automobilístico nacional dependa da capacidade de colocação de boa parte da produção no mercado internacional, a baixa relação entre número de habitantes e número de autoveículos observada no Brasil aponta para um mercado com grande potencial de vendas.

Ao longo dos anos 90, a indústria automobilística brasileira foi objeto de diferentes políticas que buscavam a reestruturação do setor. Inicialmente, por meio dos acordos de 1992 e 1993 no âmbito da câmara setorial, observa-se uma inflexão nos principais indicadores de desempenho da indústria automobilística nacional, cujos patamares de produção e vendas alcançam níveis significativamente superiores àqueles verificados no período imediatamente anterior (Zauli, 1997).

Posteriormente, com o Regime Automotivo, em um contexto marcado pelo rebaixamento do nível de proteção tarifária da economia nacional, a elevação das alíquotas de importação de autoveículos, a redução das alíquotas de importação dos insumos utilizados pelas montadoras e o privilégio concedido às montadoras locais de importar autoveículos com tarifa reduzida configuraram a nova política para o setor como um caso típico de proteção a um segmento específico da cadeia produtiva do setor automobilístico: a indústria montadora.

\section{REAÇÕES AOS REGIMES AUTOMOTIVOS}

A propósito dos focos de oposição ao Regime Automotivo nacional e ao regime especial para as regiões Norte, Nordeste e Centro-Oeste, podem ser detectadas reações provenientes de diferentes atores.

É importante notar que nem todas as empresas montadoras com investimentos planejados para o mercado brasileiro aderiram ao Regime Automotivo. A propósito, acompanhando decisão da Toyota, em dezembro de 1997 a Peugeot anunciou sua disposição de manter-se fora do âmbito do Regime Automotivo, por considerar desvantajoso assumir todos os compromissos inerentes à adesão da montadora àquele regime, preferindo optar pela estratégia de trazer da Argentina peças e carros fabricados em sua unidade local. Entretanto, de parte da Associação Nacional de Fabricantes de Veículos Automotores (Anfavea) a instituição de um regime automotivo semelhante ao argentino foi saudada como um indicativo de que o governo brasileiro estaria disposto a avançar na direção do estabelecimento de regras comuns para a integração do setor automotivo no âmbito do Mercosul, uma antiga reivindicação das empresas montadoras.

$\mathrm{Na}$ área fiscal, diversos analistas consideraram exagerados e desnecessários os incentivos embutidos no Regime Automotivo. Em primeiro lugar, estes incentivos não foram condicionados à manutenção e à criação de novos empregos por parte das empresas beneficiadas. Também não consta do Regime Automotivo qualquer cláusula relativa à transferência de tecnologia e, além disso, pelo menos parte dos investimentos no âmbito do regime automotivo viriam para o Brasil mesmo na 
ausência de qualquer incentivo de natureza fiscal. Neste último caso, estaria ausente uma das condições que justificam a concessão de incentivos fiscais, a saber, a oportunidade de uso privado de recursos econômicos, que não seria aproveitada no território nacional caso o incentivo não fosse concedido.

Inserindo-se em um contexto de profundas mudanças no âmbito das políticas regulatórias no Brasil, a disputa entre os diversos estados brasileiros pela localização de novos investimentos traduz um processo de deslocamento das políticas de atração e incentivo ao investimento do âmbito federal para o âmbito estadual, compesado ônus fiscal para as unidades da federação que, dispostas a influenciar nas decisões privadas de localização industrial, lançam mão de sua competência sobre nosso principal imposto sobre o valor agregado, o ICMS, enquanto instrumento de barganha na disputa por novos investimentos. Embora do ponto de vista nacional o ICMS seja um imposto sobre o consumo, sob a ótica de cada estado o ICMS é um imposto híbrido de origem mista incidindo sobre a produção, a circulação e o consumo. Dadas estas características, são fortes os incentivos para que cada estado procure atrair novos investimentos através da concessão de vantagens tributárias para as empresas localizadas em seu território; o que não seria possível no caso da adoção do princípio de destino para a tributação das operações comerciais interestaduais (Varsano, 1997) .

Em relação às condições que justificam a adoção de medidas de targeting industrial, o Regime Automotivo foi questionado sob diferentes aspectos: ausência de spillovers tecnológicos; inexistência de falhas de mercado que justificassem medidas de fomento setorial; baixo coeficiente de mão-de-obra e inexistência de rendas monopolistas externas cuja captura, através de benefícios à indústria nacional, beneficiaria a economia nacional (Bedê, 1997).

Outro foco de críticas aos efeitos do Regime Automotivo relaciona-se com suas consequências para os preços praticados pelas montadoras locais. Com efeito, a partir do final de 1995 observa-se uma elevação dos preços reais dos automóveis produzidos internamente (Gráfico 1). Na medida em que ampliou o horizonte de proteção para os produtores domésticos, a adoção do Regime Automotivo propiciou condições para uma elevação real da ordem de $16 \%$ nos preços dos veículos (De Negri, 1997). Diante da redução de custos de peças, componentes e bens de capital propiciada pelas regras do Regime Automotivo e do aumento de produtividade decorrente da redução de mão-de-obra, os ganhos das montadoras redundaram na ampliação de sua margem de lucro, sem qualquer transferência de benefícios para consumidores e trabalhadores da indústria.

O impacto do regime automotivo na balança comercial foi outro foco de divergências. A propósito, para o ano de 1996, montadoras e fabricantes de autopeças foram responsáveis por um déficit comercial da ordem de US\$ 1,4 bilhão. Em relação ao setor de autopeças, observa-se uma deterioração progressiva de seus saldos comerciais nos últimos anos. No $1^{\circ}$ semestre de 1997, as montadoras foram

5 “A guerra fiscal entre estados veio para ficar”. In: Gazeta Mercantil, 22/10/97. 
responsáveis por um déficit da ordem de US\$ 700 milhões (exportações de US\$1,4 bilhão e importações de US\$ 2,1 bilhões). Para o mesmo período, as importações de autopeças cresceram cerca de $40 \%$ em comparação com o ano anterior.

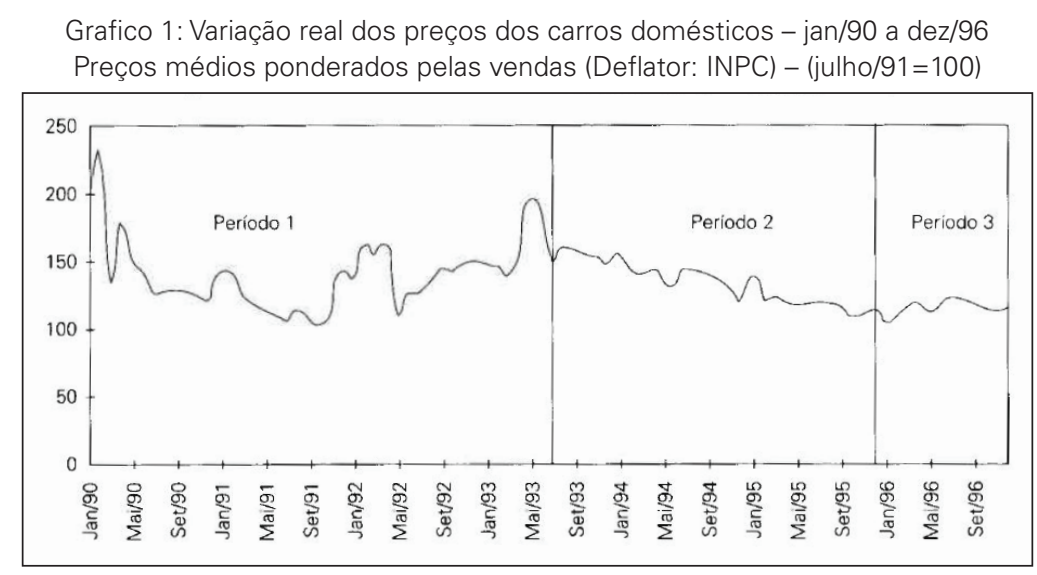

Fonte: Banco de dados sobre indústria automobilística - DIPPI/PEA. Apud, De Negri (1997).

Diante dos resultados da balança comercial do setor automotivo em 1996, e temendo que suas exportações não reagissem em 1997, Francisco Dornelles, ministro da Indústria, Comércio e Turismo, manifestou em julho a disposição em auditar as empresas do setor no sentido de colher subsídios para o monitoramento do desempenho comercial das empresas por parte do governo. Embora a cláusula de paridade entre importações e exportações não pudesse ser considerada como descumprida pelas empresas, já que o Regime Automotivo previa que o equilíbrio tivesse como base um período de três anos, Dornelles preocupava-se com a perspectiva de que o "adiamento" de exportações comprometesse a meta de equilíbrio com a qual as empresas haviam se comprometido. Em meados de setembro, a importação sem registro para efeito de compensação de 30 mil veículos pela Ford corroborou a avaliação de que era necessário um acompanhamento minucioso do desempenho comercial das empresas beneficiadas pelo Regime Automotivo. Na esteira deste incidente, em meados de outubro de 1997 a Ford encaminhou ao governo brasileiro um relatório indicando a previsão de déficit de $10 \%$ em sua balança comercial a ser compensado subsequentemente.

Ao longo do $2^{\circ}$ semestre de 1997, diante da instabilidade financeira nos mercados asiáticos, das dificuldades financeiras e do processo de reestruturação do grupo sulcoreano Kia, proprietário da Asia Mortors do Brasil, a perspectiva de não-cumprimento dos acordos firmados no âmbito do regime automotivo especial por parte de algumas empresas tornou-se motivo de preocupação. Particularmente em relação aos investimentos no âmbito do regime automotivo especial, não obstante o entusiasmo que contaminava a retórica governamental, já em meados de 1997 poucos acreditavam que todos os investimentos anunciados seriam realizados. Prevendo a possibilidade de que o regime especial fosse utilizado por empresas 
interessadas em realizar importações sem qualquer contrapartida em exportações, o governo decide-se por limitar a aprovação dos pedidos de importação destas empresas ao equivalente a $30 \%$ dos investimentos realizados e comprovados.

Em relação à oposição externa aos regimes automotivos nacional e especial, o argumento das autoridades brasileiras nos fóruns de negociação internacional pautavam-se pela necessidade de adoção de uma política para o setor automobilístico que fosse compatível com as regras temporárias aprovadas pela Argentina junto à OMC. No âmbito do Mercosul, argumentava-se, a continuidade do processo de integração econômica regional dependeria da adoção de políticas semelhantes de atração de novos investimentos entre os países-membros (BNDES, 1995b; Vigevani \& Veiga, 1997).

Contudo, após a edição da medida provisória $\mathrm{n}^{\circ}$ 1.024/95, o governo argentino qualificou a decisão brasileira de incluir os veículos provenientes da Argentina no sistema de cotas como um desrespeito aos compromissos firmados no Protocolo de Ouro Preto ao final de 1994. As reações no âmbito do Mercosul, particularmente da Argentina, ao Regime Automotivo culminaram com a decisão do governo brasileiro de excluir o comércio intrazona do regime de cotas.

No início de 1996, o Brasil passa a adotar um regime de transição similar ao argentino. Institui-se o comércio livre de veículos entre os dois países sujeitos aos requisitos de desempenho estabelecidos pelos respectivos regimes nacionais (importações a serem compensadas com exportações a qualquer destino), e ambos os países reconhecem mutuamente a vigência de seus regimes até 31 de dezembro de 1999. Com relação às autopeças, fica estabelecido:

a) o livre comércio (tarifa zero e ausência de cotas) para aquelas que fossem originárias da sub-região, as quais seriam consideradas como nacionais do país importador para efeito do cálculo do índice médio de nacionalização de veículos acabados, sempre e quando houvessem sido compensadas com exportações a qualquer destino;

b) o livre comércio para autopeças brasileiras destinadas ao mercado de reposição argentino;

c) a aceitação por parte do Brasil das autopeças importadas da Argentina para efeito do cumprimento do requisito de conteúdo nacional previsto no âmbito do programa do "carro popular"; de forma que os veículos produzidos na Argentina e que cumprissem as exigências do regime do "carro popular" fossem considerados nacionais.

No final de janeiro de 1996, o Brasil submeteu à OMC sua nova política para o setor automobilístico (medida provisória $\mathrm{n}^{\circ} 1.235$ de 14/12/95, reeditada como

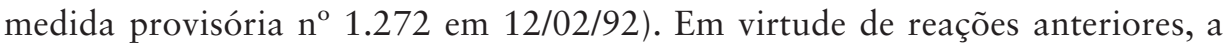
nova MP eliminava as cotas de importação e reduzia tarifas de importação de bens de capital e peças para a produção de veículos pelas montadoras instaladas no país. Não obstante, Japão e Coréia do Sul — países até então sem nenhuma montadora instalada no país-, principalmente, levantaram objeções semelhantes àquelas que haviam sido feitas à política anterior.

Em agosto de 1996, o Japão pediu consultas formais na OMC e pleiteou que 
o Brasil aumentasse a cota de exportação com tarifa reduzida de 50 para 70 mil veículos. Em outubro de 1996 foi a vez dos EUA reivindicarem uma cota de 12 mil caminhões durante 12 meses para duas de suas montadoras, a Navistar e a Caesa. No início de 1997, novas pressões, agora sob a forma de um pedido de consultas formais na OMC por parte dos Estados Unidos e da União Européia, foram motivo de preocupação por parte do governo brasileiro. Da parte da União Europeia, as principais objeções diziam respeito ao índice de nacionalização de $60 \%$ dos insumos utilizados na produção de veículos sob o regime automotivo e à vinculação entre incentivo de importação e desempenho exportador. $\mathrm{Na}$ ocasião, o representante da União Europeia encaminhou ao ministro das relações exteriores, Luis Felipe Lampréia, a reivindicação de ampliação da cota de exportação de 9.700 veículos com alíquota reduzida para montadoras europeias não instaladas no Brasil. Nessas circunstâncias, como válvula de escape, o expediente brasileiro consistiu na inclusão da montadora francesa Peugeot no sistema de cotas.

Em relação às reivindicações dos EUA, no início de 1997 o risco de um pedido de panel (comitê de julgamento) na OMC parecia contornado com a disposição declarada da empresa norte-americana Navistar de se instalar no Brasil e com a pressão de suas maiores montadoras - General Motors, Ford e Chrysler — em favor da manutenção do regime automotivo nacional. Entretanto, depois de consultas formais pelos EUA junto à OMC em fevereiro de 1997, em abril o governo brasileiro acenou com a perspectiva de flexibilização de alguns aspectos do Regime Automotivo: propôs a antecipação em um ano (até 31/12/98) do prazo para que novas montadoras que se instalarem no país façam parte do Regime Automotivo; a equalização dos bônus incidentes sobre as compras de bens de capital nacionais e importados através da eliminação da vantagem adicional de $20 \%$ concedidos sobre as compras nacionais; e a atenuação das exigências relativas às exportações para efeito de comércio compensado (permissão de importações de US \$1,01 para cada dólar exportado, já em 1997; US\$1,02 e US\$1,03 em 1998 e 1999, respectivamente). A viagem do presidente Bill Clinton ao Brasil em outubro de 1997 propiciou o ambiente para que os técnicos de ambos os países chegassem a um acordo em relação às propostas brasileiras de flexibilização. Em março de 1998 Brasil e EUA fecharam um acordo bilateral mediante o qual o Brasil permite que as montadoras que aderiram por último ao regime automotivo possam cumprir suas metas de exportação mesmo depois de sua extinção em $1^{\circ}$ de janeiro de 2000. Outra concessão feita pelo Brasil relaciona-se com a antecipação do prazo para a adesão de novas empresas ao regime automotivo, de 31 de dezembro de 1999 para 30 de junho de 1998 no caso de montadoras, e para 31 de dezembro de 1998 para as empresas de autopeças. Além disso, foram alteradas as metas de desempenho exportador por parte das empresas beneficiadas no âmbito do regime: um dólar exportado para cada US\$1,02 importado com tarifa preferencial no período de $1^{\circ}$ de julho de 1998 a 30 de junho de 1999; um dólar exportado para cada US\$ 1,03 importado de $1^{\circ}$ de julho a 31 de dezembro de 1999.

Quanto às resistências no âmbito do Mercosul, em janeiro de 1997 uma delegação argentina desembarcou em Brasília para tratar do novo quadro criado pela 
medida provisória que criou o regime especial para as regiões Norte, Nordeste e Centro-Oeste. A Argentina pretendia que os países membros do Mercosul assumissem o compromisso de não adotar políticas de incentivo fiscal regional sem antes consultar os demais sócios do bloco econômico, além de reivindicarem franjas no comércio bilateral envolvendo a exportação de 30 mil veículos em 1997, 40 mil em 1998 e 50 mil em 1999.

Em relação aos pleitos da Argentina, a estratégia de negociação brasileira inicial consistiu em deixar claro que os acordos de união aduaneira no âmbito do Mercosul não tratavam da questão dos incentivos para o desenvolvimento regional, embora tenha admitido que algumas derrogações tarifárias da medida provisória do regime automotivo especial fossem superiores às do regime automotivo geral. Além disso, os pleitos de exportação argentinos foram considerados como sendo excessivos e incoerentes com a política brasileira de estímulos a novos investimentos. Entretanto, com o desenvolvimento das negociações bilaterais, o governo brasileiro firmou um acordo visando minimizar os efeitos dos incentivos do regime automotivo especial sobre a economia argentina. Através do reconhecimento das cotas de comércio não-compensado acordadas ao final de 1994 (as franjas), o Brasil comprometeu-se em importar 85 mil veículos a título de compensação do déficit comercial argentino, além de ceder em parte às pressões argentinas ao aceitar a importação com alíquota zero das cotas de veículos reivindicadas pela Argentina entre 1997 e 1999.

A propósito de suas solicitações, União Européia e Brasil realizaram, em junho de 1997, consulta formal sobre o Regime Automotivo. Procurando evitar que as divergências entre as partes conduzissem a um pedido de panel, o Brasil admitiu fazer algumas modificações que não implicassem a descaracterização do Regime Automotivo, além de promover uma ligeira elevação da cota de veículos (de $10 \mathrm{mil}$ para 12 mil) para a União Europeia. Temendo que o exemplo brasileiro se disseminasse por outros países, e diante de um pedido de panel contra a Indonésia, os representantes da União Européia descartaram um acordo que não envolvesse o respeito pelo Brasil dos princípios de livre comércio consagrados no âmbito da OMC. ${ }^{6}$. Frente às resistências europeias potencializadas pelo Japão, o Brasil decidiu pela manutenção da cota de 50 mil veículos com alíquota favorecida, reduzindo-a, porém, de $35 \%$ para $31,5 \%$, alcançando $24,5 \%$ a partir de janeiro de 1998 , além de promover uma redistribuição das cotas de importação entre Japão, União Europeia e Coréia do Sul.

\footnotetext{
${ }^{6} \mathrm{O}$ elemento decisivo que faz com que a política automotiva da Indonésia seja menos assimilável pela comunidade internacional relaciona-se com o fato de que envolve proteção e benefícios a uma única empresa formada pela associação da sul-coreana Kia Motors com a PT Timor Putra National Company, empresa dirigida por um dos filhos do presidente Suharto.
} 


\section{AUTOPEÇAS}

No contexto de implementação do Regime Automotivo, o setor de autopeças nacional tem-se ressentido de uma política de "covardia competitiva" decorrente das medidas que facilitam as importações de autopeças através da redução de alíquotas vis-à-vis as políticas de valorização cambial e de altas taxas de juros impostas aos produtores nacionais, tendo criticado o acordo bilateral Brasil-Argentina como nocivo aos interesses das empresas de autopeças locais em decorrência do índice de nacionalização e da exigência de compensação presentes no regime automotriz argentino.

Profundamente afetado pelas políticas de redução de custos, busca de qualidade, transferência dos gastos com P\&D e de outras responsabilidades e atribuições dentro da cadeia produtiva para os fornecedores, e pelas estratégias complementares de global sourcing e montagem de uma rede de fornecedores localizados nas suas proximidades por parte das montadoras (local sourcing), o setor de autopeças brasileiro tem sido impactado diretamente pelas novas disposições institucionais adotadas no âmbito do Regime Automotivo. No contexto de gestação de um novo padrão de relacionamento entre montadoras e fornecedores, em que as indústrias de autopeças deparam-se com exigências crescentes em termos de capitalização, capacidade de investimento, modernização gerencial, logística, desenvolvimento tecnológico, entre outras, as empresas nacionais ressentem-se das dificuldades de acompanhar os programas de investimentos das montadoras, particularmente em uma situação de crescimento das importações e de ingresso de novos fabricantes internacionais no mercado nacional (BNDES, 19976; 1997c; Santos, 1997; Santos \& Costa, 1995; 1996).

Neste contexto, os novos regimes de suprimento das montadoras locais se constituem em uma resposta à novas condições que redefinem as estratégias competitivas das empresas em decorrência de alterações na configuração de variáveischave na determinação da intensidade da concorrência e da rentabilidade empresarial.

Particularmente ilustrativa das tendências de reconfiguração das relações entre empresas montadoras e fornecedores, as inovações em torno do projeto do consórcio modular em desenvolvimento na fábrica de ônibus e caminhões da Volkswagem em Rezende, no estado do Rio de Janeiro, significam um passo adiante no sentido da economia de investimento por parte das montadoras via transferência de responsabilidades para seus fornecedores. Depois do just intime, da participação no desenvolvimento conjunto de projetos com as montadoras e do fornecimento de subconjuntos, por que não localizar pelo menos uma parte dos fornecedores dentro das instalações das montadoras, transferindo a eles tarefas antes desempenhadas por funcionários das montadoras (Arbix \& Zilbovicius, 1997; Salerno, 1997)?

Embora o setor de autopeças venha apresentando crescimento do faturamento desde o início dos anos 90, observa-se uma deterioração no desempenho financeiro deste segmento, cujas margens vêm sendo comprimidas em função dos target price e target cost estabelecidos pelas montadoras. Além disso, o setor depara-se 
com uma situação em que o ritmo de crescimento das exportações não tem acompanhado o crescimento das importações. Diante da notável debilitação do poder de negociação dos fornecedores frente às empresas contratantes; da redução das barreiras de entrada para novos produtores de autopeças e intensificação da concorrência; e do aumento da elasticidade de substituição de autopeças por parte das montadoras, o Regime Automotivo dá às empresas montadoras um maior poder de barganha frente aos seus fornecedores, sem contemplar medidas que pudessem contribuir para que a modernização dos produtores de autopeças tornasse possível sua participação em um mercado em processo acelerado de internacionalização. ${ }^{7}$

Por certo, enquanto fenômeno econômico, as formas de subcontratação/ter ceirização não são inaugurais ou típicas do capitalismo contemporâneo, nem res tritas ao nascimento e desenvolvimento da indústria automobilística. As relações de subcontratação surgem concomitantemente à própria divisão social do trabalho capitalista, em um processo de especialização da produção, sendo que a focalização do fenômeno da subcontratação implica na explicitação das relações funcionais entre diferentes unidades produtivas.

Pode-se dizer que a subcontratação se apresenta como um processo estabelecido, basicamente, nas situações de menor complexidade, entre dois agentes: uma empresa primária (contratante) e uma empresa secundária (subcontratada). Esse processo materializa-se através da criação de relações de troca que vinculam a empresa contratante à empresa subcontratada e que operam no sentido de uma maior descentralização empresarial por meio de estratégias de desverticalização.

As práticas de subcontratação definem formas de coordenação entre unidades produtivas inseridas em um quadro de divisão do trabalho. Em relação às grandes empresas, as estratégias de subcontratação representam a renúncia, que pode ser temporária e é de natureza condicional, sobre o controle de determinadas fases do processo produtivo em favor das empresas subcontratadas.

Duas características são especialmente relevantes nas relações de subcontratação. De um lado, essas relações são marcadas por traços de substituição; por outro lado, manifesta-se a dimensão da subordinação entre as partes contratadas. O processo de substituição relaciona-se com a transferência de atividades antes desempenhadas pela empresa matriz para a empresa subcontratada. Já a dimensão da subordinação diz respeito à criação de laços de dependência de mão dupla entre fornecedor e contratante. No quadro de revisão das relações entre montadoras e empresas de autopeças, o papel de crescente destaque desempenhado por alguns fornecedores só encontra limite na capacidade única por parte das montadoras de operar enquanto agente especializado na organização de toda a complexidade do processo de montagem envolvido na produção de autoveículos (Hatzfeld, 1997).

Subjacente à atual dinâmica de transformação estrutural do setor de autopeças

\footnotetext{
${ }^{7}$ Os desafios enfrentados pelas indústrias do segmento de eletrônica embarcada são ilustrativos da vulnerabilidade do setor de autopeças nacional diante da competição dos grandes produtores globais. Ver a respeito BNDES, 1995.
} 
nacional, as mudanças nas estratégias das empresas montadoras definem um movimento no sentido da desverticalização da produção por intermédio da constituição de um sistema hierarquizado de fornecedores inspirado no modelo da lean production (Womack, Jones \& Roos, 1992). A adoção das linhas básicas deste modelo vem acompanhada de um processo de intensa reestruturação produtiva, desconcentração geográfica via ocupação de áreas greenfield, e de internacionalização do setor de autopeças (Posthuma, 1997). Com efeito, a dinâmica presente e futura do setor de autopeças tende a ser determinada por decisões empresariais por parte das empresas montadoras com implicações sobre as estratégias de manufatura destas empresas quanto à decisão de produzir ou comprar (make or buy) os insumos de que necessitam (Tauile, 1994).

$\mathrm{Na}$ definição das condições de suas relações com as empresas subcontratadas, as montadoras locais vêm se utilizando, nos termos da teoria da firma motriz, de sua capacidade, enquanto empresas de grande porte, de operar como unidades motrizes básicas geradoras de processos de integração complementar. De maneira congruente com alguns dos desenvolvimentos teóricos das teorias da localização industrial, em virtude de seus objetivos as montadoras têm procurado influenciar as decisões de localização dos fornecedores de autopeças de maneira a viabilizar seus esforços no sentido da transição para o modelo da lean production. Valendose de sua condição oligopsônica ou monopsônica, a grande empresa dispõe de mecanismos de pressão sobre sua base de fornecedores que a colocam na situação de poder escolher a forma de organização do processo de trocas.

Quanto a isso, a distinção entre mercado e hierarquia é fundamental. Nos termos de um arcabouço analítico clássico, mercados e firmas se constituiriam em diferentes modos de governance ou mecanismos alternativos e/ou complementares de organização das trocas econômicas. ${ }^{8}$ Dados os elevados custos de transação e os riscos de oportuismo ${ }^{9}$ associados à operação dos mercados, os processos de subcontratação se constituem em respostas das firmas no sentido da minimização daqueles custos através da escolha dos mecanismos mais apropriados aos seus objetivos..$^{10}$ Dadas suas opções, as empresas se situam em diferentes pontos ao longo de um continuum hierarquia/mercado, em função do grau de controle da empresa matriz sobre os ativos necessários nas diferentes etapas de processo produtivo (se a empresa é proprietária de todos os ativos, tem-se a opção pela hierarquia; se a empresa adquire de outras firmas no mercado seus insumos, tem-se uma estrutura comandada pelo mercado).

\footnotetext{
${ }^{8} \mathrm{O}$ conceito de modo de governance é utilizado aqui por referência aos arranjos institucionais que definem as formas e mecanismos de coordenação e cooperação econômica entre diferentes agentes

${ }^{9}$ A noção de oportunismo diz respeito à incongruência do comportamento ex-ante e ex-post uma situação contratual.

${ }^{10}$ Nos termos da teoria dos custos de transação, o tamanho das firmas é limitado por sua capacidade de produzir internamente com custos de produção e de transação inferior es àqueles nos quais se incorre na produção de mercado.
} 
Seguindo a formulação pioneira de Coase (1937), fartamente ilustrada pela abordagem histórica de Chandler $(1977,1978)$, mais tarde desenvolvida por Williamson $(1975,1985)$ e elemento central na caracterização do regime de acumulação norte-americano que emerge no último quartel do século XIX, parte de uma tipologia de ciclos sistêmicos de acumulação de capital que conformaram a economia capitalista mundial (Arrighi, 1994); a característica econômica distintiva da era da produção em massa foi um processo muito bem-sucedido de controle e redução dos custos de transação por parte de grandes organizações verticalmente integradas através da internalização de atividades anteriormente realizadas por empresas independentes, por meio da concentração das atividades empresariais. Através da substituição da coordenação das atividades econômicas pela mão invisivel do mercado por uma coordenação das diferentes atividades na cadeia de produção de cada empresa pela mão visivel das hierarquias organizacionais da corporação moderna, tem-se um processo de desenvolvimento de hierarquias administrativas voltadas, no limite, para o controle de todos os elos da cadeia de produção e comercialização de cada empresa.

Do ponto de vista das relações inter-firmas, os anos 50 se constituem em um ponto de inflexão relativamente às características do regime de acumulação norte americano da era da produção em massa (Womack, Jones \& Roos, 1992). Com efeito, a partir da experiência pioneira da Toyota, as estratégias de verticalização da produção por intermédio da construção de grandes hierarquias organizacionais vão ser postas em xeque pelo sistema japonês de subcontratação inter-firmas. De fato, a propósito da reestruturação de nosso setor de autopeças, pode-se detectar ao longo do processo de desenvolvimento do Japão no período pós-guerra certos padrões cujas tentativas de reprodução são responsáveis por algumas das mudanças em curso no padrão de relação montadoras/autopeças no Brasil.

Diferentemente das estratégias de suprimento adotadas pelas empresas americanas e europeias, o sistema japonês de fornecimento de componentes para as grandes montadoras japonesas foi resultado de um baixo grau de verticalização da produção. Em um sistema de subcontratação multiestratificado (Arrighi, 1996; Womack, Jones \& Roos, 1992), inseridos em uma estrutura de formato piramidal, os fornecedores de primeiro vínculo, localizados no vértice da pirâmide, encarregam-se de fornecer subsistemas completos ou componentes às montadoras sob forma de just in time. Estes fornecedores de primeiro vínculo, por sua vez, estabelecem suas relações de compra com fornecedores de segundo nível, que, por seu turno, relacionamse com empresas menores, e assim subsequentemente. Os fornecedores diretamente vinculados às montadoras muitas vezes assumem a responsabilidade pelo projeto, produção e controle de qualidade dos subsistemas e componentes fornecidos, em um padrão de cooperação de longo prazo entre montadoras e fornecedores.

A articulação deste padrão ocorre inicialmente no âmbito do processo de substituição dos antigos zaibatsu (grandes empresas holdings desarticuladas durante o período de ocupação norte-americana) japoneses por novos conglomerados (keiretsu) compostos por um conjunto de empresas horizontalmente conectadas e ver- 
ticalmente integradas que, tendo como objetivo a redução do grau de incerteza em sua operação, ao lado de redes informais de cooperação entre empresas informam a constituição de uma teia de relações caracterizadas por uma combinação sui generis dos princípios do mercado e da hierarquia (Kesseler, 1996).

Algumas das características que diferenciam a natureza dos regimes de subcontratação japoneses de outras experiências são particularmente relevantes dada sua afinidade com as tendências observadas nas relações de subcontratação do setor automobilístico brasileiro. Em primeiro lugar, tem-se um grau de descentralização empresarial muito mais significativo do que aquele verificado até então nas experiências ocidentais. Em segundo lugar, as redes de subcontratação japonesas se constituem em formas mais eficazes de cooperação vertical e horizontal entre empresas matrizes e subcontratadas, entre subcontratadas, e entre estas e empresas comerciais e fornecedoras de matérias-primas. Finalmente, verifica-se a precarização das relações de trabalho nos níveis inferiores das redes de empresas (Arrighi, 1996). Estes são, com efeito, alguns dos elementos que vão constituir a base para o desenvolvimento da lean production na área de suprimentos das indústrias montadoras japonesas e que vão, posteriormente, ser paulatinamente incorporados pelas demais indústrias.

As perspectivas atuais apontam para a consolidação de uma nova configuração do perfil do setor de autopeças no Brasil. Se até os anos 80 o mercado nacional de autopeças era abastecido fundamentalmente por empresas nacionais de pequeno e médio porte, a reconfiguração da estrutura do setor nos anos 90 abre espaço a um processo de desubstituição de importações e de crescente penetração de grandes empresas internacionais (Laplane \& Sarti, 1997). Embora a rigor não se possa falar de uma simples transposição dos arranjos japoneses para o complexo do setor automobilístico brasileiro nos anos 90, já que ocasionalmente as empresas produtoras de autopeças aqui localizadas encontram-se inseridas em redes de empresas que conformam estruturas de suprimento com formato distinto da estrutura piramidal característica do padrão de suprimentos japonês, tem-se a reprodução de um sistema hierarquizado de fornecedores que comporta uma série de assimetrias entre os padrões da relação montadoras/fornecedores de primeiro nível, e os padrões de relação destes últimos com as empresas que se situam nos níveis imediatamente inferiores da pirâmide.

\section{CONSIDERAÇÕES FINAIS}

No nível internacional, detectam-se diferentes estratégias de parte das montadoras com relação a seus fornecedores. A esse respeito, com relação à configuração de sua cadeia de suprimentos, o segmento das montadoras do setor automobilístico nacional caracteriza-se, hoje, pela convivência de diferentes soluções por parte das empresas. De fato, conforme a empresa de que se trate tem-se, em maior ou menor grau e sob diferentes combinações, a solução fordista clássica do "faça tudo você mesmo no interior de sua empresa" (Henry Ford); a receita de internalização 
da produção dos suprimentos através da constituição de unidades de negócio e centros de lucros independentes (Alfred Sloan); tentativas de constituição de redes de empresas nos moldes do modelo toyotista (Taiichi Ohno); até as novas estratégias de modularização da produção e montagem (José Ignácio Lopez de Arriortúa).

No âmbito das montadoras e da indústria de autopeças no Brasil tem-se verificado uma série de mudanças que respondem pelo avanço da produtividade e melhoria da qualidade dos produtos no setor. A tendência é no sentido da obtenção de uma maior hierarquizaçãoe redução do número de fornecedores; progressos com relação à qualidade; número crescente de entregas just in time; redução de estoques; contratos de prazos mais longos; e maior participação dos fornecedores nos projetos e engenharia de produtos.

Entretanto, ainda estamos longe de alcançar as bases do fornecimento enxuto no setor. Para tanto, seria necessária a operação de uma mudança nas relações montadoras/fornecedores no sentido do estabelecimento de linhas de conduta cooperativas que permitissem a superação dos círculos viciosos da interação somazero típica do padrão de relações da era da produção em massa e o estabelecimento de um novo padrão por intemédio do qual montadoras e fornecedores pudessem compartilhar custos e oportunidades em períodos de alta e de baixa nos negócios do setor.

Historicamente, desde os anos 50, quando ganha impulso a constituição de um parque industrial de autopeças no Brasil, sob determinadas conjunturas político econômicas marcadas pela disposição governamental em intervir nas relações fornecedores/montadoras visando o estabelecimento de relações de mais longo prazo e por uma certa dose de restrição às importações, os fornecedores aqui localizados foram capazes de desenvolver padrões de relação horizontalizadas e até certo ponto cooperativas nas suas relações com as empresas montadoras. O desafio presente reside em reproduzir tais arranjos em um contexto de liberalização da economia e de resistência por parte do Estado em definir políticas de proteção e estímulo adequadas à indústria de autopeças (Addis, 1997).

Envolvidas com a estruturação de um novo sistema de suprimentos, as montadoras instaladas no país lançam mão de estratégias diferenciadas e combinadas na definição das bases do relacionamento inter-firmas no setor, conformando um conjunto de relações regidas tanto pelos princípios do mercado quanto por aqueles da hierarquia; sendo o fenômeno da subcontratação decorrente de novas relações de custo-benefício que favorecem a estruturação de operações de mercado em detrimento das relações extramercado.

\section{REFERÊNCIAS BIBLIOGRÁFICAS}

ADDIS, Caren. (1997). “Cooperação e desenvolvimento no setor de autopeças”. In: Arbix, Glauco e Zilbovicius, Mauro (orgs.). De JK a FHC. A Reinvenção dos Carros. Scritta. São Paulo.

AMADEO, Edward. (1995). "Contra a inevitabilidade dos paradigmas: uma agenda de política industrial”. In: Velloso, João Paulo dos Reis (org.). O Real e o Futuro da Economia. José Olympio. Rio de Janeiro. 
AMATO Neto, João. (1995). “Reestruturação Industrial, Terceirização e Redes de Subcontratação”. In: Revista de Administração de Empresas, v.35, n.2, pp. 33-42.

AMCHAM Brasil - American Chamber of Commerce. (1997). "Chrysler Returns to Brazil in Time for Mercosul Trade Rush”. In: The Brazilian Investment Guide 97/98. São Paulo.

ANFAVEA. (1997). Anuário Estatístico.

ARBIX, Glauco \& ZILBOVICIUS, Mauro. (1997). “O Consórcio Modular da VW: um novo modelo de produção?” In: Arbix, Glauco e Zilbovicius, Mauro (orgs.). De JK a FHC. A Reinvenção dos Carros. Scritta. São Paulo.

ARRIGHI, Giovanni. O Longo Século XX. (1996). Contraponto/UNESP. Rio de Janeiro/São Paulo.

BEDÊ, Marco Aurélio. (1997). "A Política Automotiva nos Anos 90”. In: Arbix, Glauco e Zilbovicius, Mauro (orgs.). De JK a FHC. A Reinvenção dos Carros. Scritta. São Paulo.

BNDES. (1995) "Eletrônica Embarcada na Indústria Automobilística".

BNDES.(1995b). "Brasil e Argentina: estratégias de integração — setor automotivo”.

BNDES.(1997a). "Novos Investimentos da Indústria Automobilística”. Informe Setorial nºl 1/Abril. Complexo Automotivo.

BNDES. (1997b). "Desempenho do Setor de Autopeças”. Informe Setorial nº12/setembro. Complexo Automotivo.

BNDES.(1997c). "Interiores: assentos automotivos e componentes de interior”. Outubro/97.

CHANDLER, Alfred. (1977). The Visible Hand: the managerial revolution in American business. The Belknap Press. Cambridge.

CHANDLER, Alfred. (1978). “The United States: evolution of enterprise”. In: Mathias, P. \& Postan, M. M. (orgs.). The Cambridge Economic History of Europe, v. VII. Cambridge University Press. Cambridge.

COASE, Richard. (1937). “The Nature of the Firm”. In: Economica, v.4, n.15.

DENEGRI, João Alberto (1997). "Elasticidades renda e preço da demanda de automóveis no Brasil”. inédito.

FREYSSENET, Michel \& LUNG, Yannick. (1996). "Entre mondialisation et régionalisation: quelles voies possibles pour l'internationalisation de l'industrie automobili?”. In: Actes du Gerpisa, n.18. Paris.

HATZFELD, Nicolas. (1997). "Component Suppliers and Manufacturers: Who Benefits from the Change in their Relations? “. La Lettre du Gerpisa, n.112. Research Questions. Paris.

KESSELER, Alex. (1996). "Evolution of Supplier Relations in European Automotive Industry: Product Development Challenge for a First Tier Supplier “. In: Actes du Gerpisa, n.19. Paris.

LAPLANE, Mariano Francisco \& SARTI, Fernando. (1997). “The Restructuring of the Brazilian Automobile Industry in the Nineties”. In: Actes $d u$ Gerpisa, n.20. Paris.

POSTHUMA , Anne Caroline. (1997). "Autopeças na encruzilhada: modernização desarticulada e desnacionalização “. In: Arbix, Glauco e Zilbovicius, Mauro (orgs.). De JK a FHC. A Reinvenção dos Carros. Scritta. São Paulo.

ROLDÁN, Martha. (1996). "Continuities and Discontinuities in the Regulation and Hierarchization of the World Automotive Industry". In: Actes du Gerpisa, n.20 . Paris.

SALERNO, Mario Sérgio. (1997). "A indústria automobilística na virada do século “. In: Arbix, Glauco e Zilbovicius, Mauro (orgs.). De JK a FHC. A Reinvenção dos Carros. Scritta. São Paulo.

SANTOS, Angela Maria Medeiros M. (1997). "Complexo Automotivo”. BNDES.

SANTOS, Angela Maria Medeiros M. \& COSTA, Cláudia Soares. (1995). “ Autopeças — um setor em transformação”. BNDES.

SANTOS, Angela Maria Medeiros M. \& COSTA, Cláudia Soares (1996) Reestruturação da Indústria de Autopeças. BNDES.

Sindicato dos Metalúrgicos do ABC. (1996). Globalização e Setor Automotivo - A Visão dos Trabalhadores. São Bernardo do Campo.

TAUILE, José Ricardo. (1994). "Flexibilidade dinâmica, cooperação e eficiência econômica: anotações”. In: Revista de Economia Política, v.14, n.1. 
VARSANO , Ricardo (1997). “A Guerra Fiscal do ICMS: quem ganha e quem perde”. IPEA. Texto para discussão n.500 . Rio de Janeiro.

VIGEVANI, Tullo \& VEIGA, João Paulo Cândia. (1997). “A Integração Regional no Mercosul”. In Arbix, Glauco e Zilbovicius, Mauro (orgs.) . De JK a FHC. A Reinvenção dos Carros. Scritta. São Paulo.

WILLIAMSON, Oliver. E. (1975). Markets and Hierarchies. Analysis and Antitrust Implications. The Free Press. New York .

WILLIAMSON, Oliver. E. (1985). The Economic Institutions of Capitalism. The Free Press. New York.

WOMACK , James; JONES, Daniel T. \& ROOS, Daniel. (1992). A Máquina que Mudou o Mundo. Campus. Rio de Janeiro.

ZAULI, Eduardo Meira. (1997). As Condições Sociais da Emergência e Decadência da Câmara Setorial da Indústria Automotiva no Brasil. Annablume Editora. São Paulo. 